\title{
1. State of the field: research on public policy and public administration in China
}

\author{
Xiaowei Zang and Hon S. Chan
}

In this Handbook, we offer students and researchers a timely discussion of research and teaching on public policy and public administration (PA) in the People's Republic of China (PRC) since the 1980s. Contributors include established scholars and emerging research stars from universities in Australia, China, Hong Kong, Macau, Singapore, South Korea, Taiwan, the UK, and the US. Their presentations have contributed to the study of PA in China with theoretical insights, empirically based findings and innovative methodologies, enabling this edited volume to depart from existing handbooks on PA in two ways. First, many existing handbooks examine general challenges and broad opportunities in PA research in different countries, yet they do not include a detailed discussion of theoretical and empirical issues in each of the countries they cover, given space limitation. In comparison, this Handbook offers detailed information on many aspects of PA in a single country, that is, the PRC.

Second, many existing PA handbooks include chapters on theoretic perspectives on different topics in PA from research in the West. They are unlikely to be very relevant for readers who are interested in empirical issues in or how existing theories from the West can be best used to guide research on PA in China. In comparison, many chapters of this Handbook combine a theoretical discussion with empirical analyses in the study of PA in China. It can serve as an important reference for graduate students and young scholars in future research in this field. This way, this Handbook can advance PA research in China. It also contributes to mainstream PA research since knowledge production in this field of inquiry is inherently comparative (Kim et al. 2019, 754-755; also Fritzen 2010; Jreisat 2005, 2011; Holzer and Zhang 2002, 2009; Yang 2018). Wu, He, and Sun (2013, 262) claimed that a discussion on the development and future direction of PA research in mainland China "could prove to be of global significance to the development of the field."

There are three objectives in this introduction chapter. The first one is to offer readers a contour of the development of PA teaching in China. The second is to discuss the current state of research on PA in China, via an examination of some good reviews of both the English literature and its Chinese counterpart on PA in China. And the third is to outline each of the chapters to guide readers through this Handbook. We conclude with a suggestion of some possible action plans to advance research on PA in China.

\section{A BRIEF HISTORY OF PA TEACHING IN CHINA}

The centralized imperial bureaucratic system was first established by the Qin dynasty (221-206 BC) after China was united in 221 BC. A civil service examination system was set up to recruit talents into the bureaucracy according to their merits, demonstrated by their examination test scores, in the Sui dynasty $(581-618 \mathrm{CE})$, and consolidated in the Tang dynasty 
(618-907 CE). The civil service examination system lasted for 1,000 years (Cartwright 2019; Miyazaki 1981). It was abolished in 1905 by the Qing government in the midst of modernization attempts.

The imperial bureaucracy and the civil service examination system had little to do with PA as an academic discipline as we understand today. While we are aware that this discipline was imported into China from abroad (Holzer and Zhang 2002; Kim et al. 2019; Li, Han, and Kim 2018; Liu and Li 2013), we do not know exactly when it made a debut in and who first introduced it to China. Citing Harris (2002), Kim et al. $(2019,754)$ asserted that Kang Youwei introduced the concept and theories of PA from Japan to China in the late 19th century. But Yang (2018) claimed that "modern PA in China is first mentioned by Liang Qichao" in the late Qing dynasty and the early Republic of China (1912-1949 CE). Liu and Li $(2013,1)$ offered a different view that PA

was first imported from the West in the 1930s. Zhang Jinjian, who is later called the "Father of Chinese PA", was trained at the Department of Political Science of Stanford University, with a focus on PA. When he came back to China with the master's degree, he also brought back his knowledge gained from Western countries.

In addition, citing Wang (2006), Kim et al. $(2019,754)$ claimed that PA was first taught as a subfield of political science in the School of Law and Politics in Guangdong province in 1904. Yet Yu, Rubin, and Wu $(2012,546)$ argued that "the origins of Public Administration as an academic discipline in China can be traced back to the 1920s when it was first introduced into the higher education curriculum as a subfield of political science." Xue (2019) asserted that "China's public administration education started in the 1930s." These different views have existed partly because information about PA teaching and research in China before 1949 is thin and sketchy.

There is not much to say about PA teaching and research in China between 1952 and 1982, as it was removed from the university curriculum during this period of time (Chow, $\mathrm{Xu}$, and Wen 2019; Kim et al. 2019; Li, Han, and Kim 2018; Mingus and Jing 2016; Xue 2019; Yu, Rubin, and Wu 2012; Yang 2018; Zhang et al. 2018; Zhao 2008). In 1982, two events occurred. First, "Xia Shuzhang, a Harvard MPA graduate in the 1940s, wrote articles and called for a systematic research of PA" in China in that year (Liu and Li 2013, 2); second, a workshop on PA was organized by the Chinese Association of Political Science in the same year. In 1984, a joint seminar on PA was held by the General Office of the State Council and the Ministry of Labor to discuss the importance and necessity of PA research and training. In 1986, the Ministry of Education categorized PA as a subject under political science, turning PA as an academic discipline in China (Kim et al. 2019; Li, Han, and Kim 2018; Yu, Rubin, and $\mathrm{Wu}$ 2012).

There has been a rapid expansion of degree programs in PA in China since then. Yang (2018) reported that Wuhan University and Zhengzhou University began to recruit undergraduate students in PA in 1986. Next, the Chinese Association of PA was founded in 1988. In 1997, "public management was recognized by the Ministry of Education as an independent category under the officially-issued catalogue of academic fields. The next year, three universities were given the authority to grant $\mathrm{PhD}$ degrees of PA" (Liu and Li 2013, 8-9). In 2000, Tsinghua University set up China's first public policy school (Xue 2019; Yang 2018; Chow, Xu, and Wen 2019; Zhao 2008) and reported that the undergraduate programs of PA at Chinese universities increased from two in 1986 to 876 (among these, 517 programs are called 
"public affairs," and 369 programs are called "public administration") in 2017, the academic master programs increased from one in 1988 to more than 200 in 2017, the professional master programs (MPA) increased from 24 in 2001 to 226 in 2017, and the $\mathrm{PhD}$ programs increased from two in 1990 to 47 in 2017.

Kim et al. $(2019,754)$ reported that the first MPA program in the United States was offered by the Maxwell School of Citizenship and Public Affairs at Syracuse University in 1924, and there were 197 MPA related programs accredited in the United States by 2018. In comparison, the PRC developed 228 MPA programs between 2002 and 2015 (also Yu, Rubin, and Wu 2012).

$\mathrm{Wu}, \mathrm{He}$, and Sun $(2013,261)$ estimated that the number of scholars in this field in China was around 1,500 in 2013. Of course, the number does not tell us everything about the mainland Chinese PA community. Liu and $\operatorname{Li}(2013,5)$ noted that "the first generation of PA scholars actually have various educational backgrounds other than PA. They learned, for example, economics, sociology, law, or political science, and later, when PA as a discipline started to develop in China, switched their foci to this new field." Zhao (2008, 51-52) found that many PA scholars were trained in arts, economics, engineering, medicine sciences, and political science, and asserted that they "started to acquire modern concepts and theories in the field in the past decade or so." Wu, He, and Sun $(2013,267,269)$ claimed that many mainland Chinese PA scholars were trained in philosophy and law. Zhao $(2008,52)$ concluded that there "is a serious shortage of professionally trained public administration educators, scholars, and researchers in universities." This situation has been improved, as there have been efforts and investments to improve the quality of domestic PA doctoral programs in China. Furthermore, more and more Chinese students with PhDs in PA from the West, Hong Kong, Japan, and Singapore have returned to work at Chinese universities in recent years.

Tong and Straussman (2003) noticed that Chinese universities adopted a Western-style professional MPA degree (also Yu, Rubin, and $\mathrm{Wu} 2012$ ). Wu and He (2009) discussed how different paradigms in PA teaching from the West impacted the selection of course content and pedagogical foci in professional curricula in top PA degree programs in China. Liu and Li $(2013,5)$ explained that "Chinese PA, due to its interrupted academic tradition, lacks theoretical legacies," and that "Chinese PA was imported from Western countries. The influence of international scholarship has never stopped since its resumption," and that "learning from the West is a realistic approach to echo back" (also Yang 2018).

\section{RESEARCH ON PA IN CHINA}

As noted, PA teaching in China has made impressive progresses since the late 1980s (Kim et al. 2019; Li, Han, and Kim 2018; Liu 1993; Zhang 1993). Is there a similar achievement in research on PA in China? To address this question, we examine the current state of research on PA in China via an examination of some good reviews of both the English literature and its Chinese counterpart on research on PA in China (Cheng and Lu 2009; Chow 1991; Chow, Xiao, and Wen 2018; Chow et al. 2019; Kim et al. 2019; Liu and Li 2013; Lu and Chow 2008; Mills and Nagel 1993; Mingus and Jing 2016; Walker, Brewer, and Choi 2014; Wu, He, and Sun 2013; Zhao 2008). We focus on the reviews on research on PA in the PRC in this section. Readers interested in research on PA in Hong Kong, Macau, and Taiwan can refer to Gao 
(2014), Lo (2014), and Chapter 26 by Wang and Gao and Chapter 27 by Sun, Chen, and Phan in this Handbook.

\section{The English Literature on PA in China}

The English literature on PA in China is part of mainstream PA research and global PA knowledge production, as it has made persistent efforts on the basis of mainstream theories and methods to address mainstream PA questions in the context of the PRC. Although it has advanced knowledge on public policy and public administration in China in the past few decades, Kim et al. $(2019,753)$ have not found "an overview of Chinese public administration research and recommended potential ways forward." What are the trends and characteristics in this growing field of inquiry? What are the main limitations in this field? And what are the opportunities and challenges presented in the English literature on Chinese PA?

Existing scholarly efforts have partly addressed the above questions. Walker, Brewer, and Choi (2014) found 309 English-language articles on PA in China, Japan, Hong Kong, Taiwan, and South Korea in 32 PA journals from the Web of Science for the period 1999-2009. They claimed that many of these articles were comparative in nature, focused upon systems of government and policies as the topic and unit of analysis, exploited reviews of secondary sources for data, and drew upon many disciplines and scholars from around the globe. They concluded that the extent of the English-language research published in PA journals as listed in the Social Science Citation Index (SSCI) was limited and largely focused on East Asia. However, Walker, Brewer, and Choi (2014) did not offer specific information about research outputs on PA in China in their paper.

Kim et al. (2019, 753, 756-757) analyzed 346 articles on PA in China published in the top 25 English-language PA journals in the world between 1996 and 2016 and showed an increase in the number (from one article in 1996 to 43 articles in 2016). Among the authors of these articles, 85 were "from the United States, 298 from Mainland China, 127 from Hong Kong, and 26 from Australia." Also, "217 articles (62.7 percent) used qualitative methods, while 117 (33.8 percent) chose quantitative methods. Only 12 studies applied mixed methods." These articles examined various issues such as "local governments, institutional governance, performance management, economic development, and administrative reform” (Kim et al. 2019, 758).

Zhang et al. $(2018,74)$ assessed the performance in mainland China's research on PA by examining publication size, impact, and scient-metric indicators, including China's global publication share, growth rate, citation impact, and leading journals based on the last 15 years of publications data, as retrieved from the SSCI database; recognized international collaborators and domestic contributors are also considered. They found that the quantity and quality of mainland China's PA research increased steadily. They predicted that mainland China scholars would continue to achieve international publishing success and discussed challenges brought about by internationalization in China. "For instance, in 2012, at least 27 special issue papers were published by mainland China scholars, out of a total of 56 publications (48 percent); this signifies the boost which 'special issues' have delivered to mainland China's research record." However, "special interest in China will no doubt decline going forward, as uniquely China-related topics may not satisfy international peers so easily in future."

Zhang et al. (2018) also claimed that mainland scholars had a relatively lower citation score. The participation of non-mainland scholars improved mainland PA publications in citation performance. For top-rated journals, apart from international collaboration, mainland scholars 
mainly depended on special issues or supplementary issues. Finally, they asked several questions about future research on PA in China: Will internationalization result in mainland scholars catering to global publication preferences? Will internationalization encourage "publishing for publication sake"? Will the international publishing preference of mainland scholars force the reform of domestic PA journals? Will the domestic market for PA journals shrink?

Overall, the English literature on PA in China include good research outputs in top PA journals with strong theoretical relevancy and innovation and rigorous research methodology, judging from the mainstream social science perspective. This is partly because many authors were educated and have worked in the West. It is encouraging that more and more mainland PA scholars have published in top English journals in recent years. Nevertheless, the English literature on PA in China is still an emerging specialty, and one of the major challenges PA scholars in the West have faced is limited access to data in China, which has limited the range of research topics they can investigate. PA scholars in the West have relied heavily on their collaborators in China for data gathering. The tightening control over academic activities in the PRC in recent years can pressurize and short-live future research by PA scholars outside China.

\section{The Chinese Literature on PA in China}

The Chinese literature on PA in China has developed rapidly, especially in terms of the range of research themes and the amount of outputs. Wu, He, and Sun (2013, 266-267) gave an incomplete list of topics under study including administrative philosophy and ethics, administrative law, crisis management, human resource management, local government, network governance, organizational theory/study, public policy, public finance and budgeting, public sector reform, and new public management (also Mingus and Jing 2016). Wu, He, and Sun (2013, 261) found that a leading Chinese-language PA journal in the PRC, Chinese Public Administration, published about 360 articles in 2008, which was more than the combined total of articles published in the same year by eight top English-language PA journals: Journal of European Public Policy, Journal of Public Administration Research and Theory, Public Administration Review, Philosophy and Public Affairs, Journal of Policy Analysis and Management, Public Administration, Journal of European Social Policy, and Governance.

Chow, Xu, and Wen $(2019,145)$ showed some breakthroughs in research on Chinese PA (CPA) by mainland scholars, "including ontological confirmation of public administration nature and identification of necessary conditions for effective administrative results." $\mathrm{Wu}$, He, and Sun $(2013,273)$ claimed that "PA scholars in mainland China are clearly ambitious in building new theories." Chow, Xu, and Wen $(2019,156)$ were hopeful that if CPA scholars "utilize the concept of social responsibility force, which is a necessary condition for 'responsible purposive authority application' in the administrative world, they are likely to make genuine contributions to the realization of PA as a basic science and a design science" in the future.

\section{Studies of Sinicized Big Questions}

Much of this growing Chinese literature on PA has been produced by mainland Chinese scholars. We divide them into two schools to simplify the discussion below. First, mainland PA scholars in one of the schools have sought inspirations from Behn's (1995) big questions 
on micromanagement, motivation, and measurement, and they are more interested than other Chinese PA scholars to develop Sinicized big questions on PA in China. Their interest was partly motivated by the warnings from 马骏/刘亚平 (2007) that PA research in China ran into an "identity crisis," as it failed to address real problems in the PRC (also Cheng and Lu 2009; Chow, Xiao, and Wen 2018; Mingus and Jing 2016).

Some of these PA scholars have proposed some possible Sinicized big questions in the Chinese context. Mingus and Jing (2016) identified and elaborated six main issues from their proposals: (1) Micromanagement: How can Chinese policy makers accelerate the development of an efficient and professional civil service while adapting their institutions for political control of society and the civil service? (2) Trust: How can professional managers increase their persuasive powers in relation to the party secretaries, toward the aim of stronger agency performance? (3) Governance: How can public managers focus on effective implementation while avoiding the appearance that they are seeking to establish or change public policy? (4) Entrepreneurship: How can local economic and social development be encouraged, yet with a strong focus on the public interest? How can state enterprises become more efficient without privatization? (5) Motivation: How can the culture of the Chinese civil service be developed to reflect the public interest rather than the personal interest? (6) Measurement: How can China use diverse measures to increase the performance of its public officials and its public agencies while also meeting political demands and obligations?

It is not clear how much and how successfully empirical research has been conducted by mainland Chinese PA scholars interested in Sinicized big questions in China. Nor is it clear what new theories and methods have been invented to study Sinicized big questions in China. Much research on domestically embedded big questions is in Chinese and not well known to scholars outside China. More importantly, while the above six issues are important, it is difficult to judge how much they are Sinicized big questions. PA scholars all over the world have examined same or similar PA questions and used same or similar concepts in their studies.

Furthermore, Lu and Chow (2008) claimed that theory-building and knowledge advancement in Chinese PA were problematic, and the field was characterized by traditionalism, conservatism, and reductionism, leading to "mediocrity in scholarship." Cheng and Lu (2009) pinpointed the inability of the mainland Chinese PA community to conduct sophisticated research and generate indigenous theories. Chow, Xiao, and Wen $(2018,22)$ argued that Chinese PA "could hardly be a source of indigenous theories to inform political-administrative practice." Hopefully, these problems may be gradually removed from Chinese PA, as more and more Chinese students with $\mathrm{PhD}$ from overseas institutions return to and work in China (Chow, Xiao, and Wen 2018, 25-26).

\section{Studies of Mainstream PA Research Questions}

Second, mainland PA scholars in another PA school in China are more interested than those in the above school to apply theories and methods from the West to the study of various PA issues in China. Walker, Brewer, and Choi (2014) found that studies published in the native languages of Hong Kong, Macau, Mainland China, South Korea, and Taiwan pointed to a robust and healthy community that actively published on topics of administration and policy. The topics studied reflect international trends in research on management reform and social policy but show distinct differences at the country level, where local debates are more of an influence on academic writing. Yang (2018) found that the number of PA articles published 
in China increased since 1986, and the three major research perspectives were politics $(51.67$ percent), management (43.6 percent), and law (2.83 percent).

$\mathrm{Wu}, \mathrm{He}$, and Sun $(2013,262)$ sampled a total of 2,566 articles published in the top three Chinese-language PA journals in mainland China between 1998 and 2008 and reported that the contributions by government officials accounted for more than 10 percent of authors in leading PA journals in China. Also, 11.8 percent of first authors in articles published in leading PA journals in mainland China were graduate students, notably higher than the proportion (2.3 percent) of graduate students among first authors for top English-language PA journals (Wu, He, and Sun 2013, 265-266). However, Wu, He, and Sun $(2013,269)$ found that

on average the articles in Chinese PA journals are much shorter than would be expected by readers of articles of similar prestige in top Western-language PA journals. The length of most articles in PA journals in mainland China (more than 75 percent) is between 3000 and 10,000 Chinese characters, the equivalent of only 2000 to 6500 words in English (given a conversion rate of 1.5:1 between Chinese characters and English words).

Also, "The average number of references in articles published in mainland China seems relatively low compared to what one customarily sees in articles published in Western language PA journals."

There is a general concern over the quality of research on PA in China by the mainland PA research community. Jing (2008) examined the quality of PA dissertations produced in China between 2002 and 2006 and claimed that the results were unsatisfactory. Lu and Chow (2008) asserted that Chinese PA scholars tended to pursue atheoretical studies and were unable to use sophisticated methodology to develop theories. Wu, He, and Sun $(2013,272)$ judged that only a small proportion of PA outputs they reviewed met international standards for the social sciences, and there is "the scarcity among mainland publications of articles covering any research methods, empirical or non-empirical - about 90 percent of these articles did not engage with any formal research methods at all." Walker, Brewer, and Choi (2014) argued that PA scholarship from some East Asian countries (including China) tended toward doing the descriptive work, and much needs to be done to improve the methodology.

Chow, Xiao, and Wen $(2018,24)$ claimed that in the 2010s, Chinese PA scholars "are still busy in producing here-and-now descriptive, thus merely generating low quality publication. Unfortunately, such a mediocre information practice has in fact been reinforced by the current academic incentive system, which rewards academicians based on the quantity of their publication, rather than quality."

Chow, Xu, and Wen $(2019,145)$ concurred that research outputs by the mainland PA research community "lacked an intellectual core that defines the nature of public administration as a professional practice, and in turn, the nature of CPA as an academic discipline." Chow, $\mathrm{Xu}$, and Wen $(2019,150)$ asserted that CPA "has been unable to generate usable knowledge to help" the Chinese government meet developmental and governance challenges.

CPA could hardly be considered a science of administration, as it does not have sufficient philosophical and intellectual underpinnings. Further, CPA suffers from three maladies, namely, reductionism, traditionalism, and conservatism, which together reinforce mediocrity. If untreated, these maladies would make CPA's redemption impossible, preventing the political-administrative theoretical breakthrough that China badly needs. (Chow, Xu, and Wen 2019, 150) 
Finally, Chow, Xu, and Wen argued $(2019,149)$ that CPA has suffered "from research deficiencies, such as researchers' tendency to pursue atheoretical studies and their incapacity to use sophisticated methodology to develop theories."

The critics of the research outputs by mainland PA researchers include scholars in and outside the PRC. They have given different reasons to justify their harsh comments on the Chinese literature on PA in China. 马骏/刘亚平 (2007) thought that PA researchers in China focused much of their attention on importing theories and practices from the West. Liu and Li $(2013,5)$ claimed that "the biggest challenge for Chinese PA lies in the failure of PA scholars to adopt scientific research...most publications on CPA are descriptive, normative, non-analytical and non-empirical, without even the simplest research design." Wu, He, and Sun (2013) lamented about inattention to research methodologies by the mainland Chinese PA community.

Chow, Xiao, and Wen $(2018,25)$ argued that Chinese PA scholars were risk-aversive researchers, opposing radical changes in their research and pedagogical pursuits:

They tend to avoid critical or creative studies, which are too scholarly taxing and politically dangerous and which produce research outputs that are often not publishable due to the conservative stance of journal editors and publishers. They would rather pursue descriptive, normative, and non-analytical research - that is, insignificant research. The inevitable consequence is their failure to enhance strategic insights and innovative ideas.

Encouragingly, Wu, He, and Sun $(2013,269,272)$ found that empirical analytic methods showed an increase in publications from mainland China, as the share of such articles increased from 1.2 percent in 1998-2001 to 7.3 percent in 2006-2008. Chow, Xiao, and Wen (2018, 25-26) reported that in the past decade more Chinese PA scholars received their doctoral education in developed regions and countries, and many top Chinese PA programs adopted the policy of recruiting scholars with a doctoral degree conferred by world class universities.

\section{CHAPTER OUTLINES}

Our third task in this introduction is to offer an outline for each chapter in this Handbook. We observe that the important topics in research on PA in China include the civil service and policy implementation in China. PA scholars in and outside China have examined them separately, however. We deem it necessary to link these two research topics to provide readers with a comprehensive and coherent lens to understand challenges and opportunities in the study of PA in China. This is a difficult task since it is perhaps a first attempt to change the status quo in research on PA in China. To a large extent, our contributors have helped us to meet this challenge in this Handbook, as discussed below.

\section{Part II: The Chinese Civil Service}

The three chapters in this section address the following questions: How are Chinese bureaucrats recruited? What are the main selection criteria? How are bureaucrats supervised, managed, and rewarded? How is civil service performance assessed? In Chapter 2, Zhiyue Bo examines the selection of local leaders in China. His chapter provides a clear definition of local leaders in China before it reviews rules and norms for selecting local leaders in China. 
It then presents theoretical debates over personal connections versus meritocracy in selecting Chinese local leaders and provides a critical assessment of this field of inquiry and reflects on its practical implications. Bo concludes his chapter by pointing to some promising ways forward for the future study.

In Chapter 3, Shuo Chen and Hon S. Chan discuss civil service pay in China with a view to elucidating the background of the pay reform. Chen and Chan argue that civil service pay is crucial to human resource management, government efficiency and integrity in public administration. They stress that China's civil service pay system is different from its Western counterparts, with a high integration of politics in civil service. Chen and Chan first review the four rounds of civil service pay reforms from 1950s to 2006. Next, Chen and Chan examine the main achievements and unfold the underlying controversies of these reforms. Based on the discussion of the recent changes of civil service pay policies, Chen and Chan then explore the prospects and major challenges surrounding the recent development of the civil service pay system. By evaluating the development of civil service pay since 1949 up to date, Chen and Chan offer readers a basic understanding of the reform process and main dilemmas of the civil service pay in China.

In Chapter 4, Jie Gao observes the embrace of performance measurement as a tool to improve the efficiency, effectiveness and accountability of the bureaucracy since the late 1970s. The embrace came in three waves. In the first wave, which began in 1979, the national leaders took the initiative to develop a cadre evaluation system and a target responsibility system (the TRS). The TRS has remained the most influential performance measurement system in local government. The second wave began in the late 1990s, characterized by the rise of third-party evaluations in assessing government performance to address the shortcomings of the TRS since it focuses on top-down evaluation and control. The third wave started in the late 2000s, when local governments at all levels were enthusiastic about developing their own evaluation systems. Gao explores the following questions on the three waves in her chapter: What are the major performance measurement systems that the Chinese leaders have adopted during the three waves of reform? How are these systems designed, and what are their key features? How effective has the implementation of these systems been in improving the performance and effectiveness of local governments? What challenges and problems do China's performance measurement reforms face if they are to go forward?

\section{Part III: Government Capacity-Building in China}

The chapters in this section discuss government capacity-building and policy making in China, to explore how governments in China are funded, what new capacities they have developed to cope with crises and other challenges in government, and how they have handled issues of transparency and accountability in an authoritarian context. In Chapter 5, Ting Gong reports that since the onset of reform in the early 1980s, the Chinese government has engaged in an intensified battle to control corruption and to promote government integrity. However, corruption has continued to surge and become increasingly rampant, threatening the legitimacy of the PRC. To partly address this problem, local government integrity initiatives and programs have proliferated in recent years. Local innovation in managing government integrity has been encouraged by the central government. Drawing on her fieldwork in Guangdong, Ting Gong addresses the question of why the central leadership has become receptive to local initiatives in cadre management, an area where political conformity was deemed necessary by an author- 
itarian regime. Ting Gong suggests that the strategic adjustment testifies to the institutional failure of the earlier anti-corruption regime that manifested in, inter alia, an acute agency loss problem. The emerging approach to integrity management nevertheless has paradoxical institutional roots. It indicates the new thinking of the central authorities on holding local governments responsible for integrity management. However, the adjustment is also driven by the center's concern about losing control and its desire to "manage" government integrity under the state's hierarchy.

In Chapter 6, Shui-Yan Tang and Bo Wen argue that China's relatively decentralized fiscal system and its highly centralized cadre management system have driven its economic growth. Yet many of the same fiscal and personnel incentives have negatively impacted other governance issues such as environmental protection projects, efforts to combat corruption, and widening income gaps. By comparing four in-depth case studies, Tang and Wen examine how the current fiscal and personnel incentives result in distorted behavior patterns among local government officials: bureaucratic entrepreneurship, reliance on extra-budgetary revenues, excessive borrowing, making the numbers regardless of outcomes, and short-sightedness. Tang and Wen challenge arguments put forward by Weingast that (1) China is a case of market-preserving federalism, and that (2) market-preserving federalism can be developed without constitutional guarantees of political freedom and democratic representation.

In Chapter 7, Liang Ma examines electronic government (e-government), which is a new form of government in the digital era, characterized by the use of various information and communication technologies in administrative procedures, public service delivery, and public participation. Ma claims that the PRC has been lagging behind in e-government, but it has been catching up rapidly in many aspects in the past decade. Ma reviews the current literature on e-government in China, identifies the key gaps in theories and research methods, and suggests future research avenues in this field. Ma finds that the research on e-government in China is split into three camps, including the assessment of e-government development, and the antecedents of e-government adoption and implementation, and the various impacts of e-government. Ma suggests that future research can explore the cross-boundary collaboration in e-government development, incorporate the behavioral science and design science into e-government studies, and pay more attention to cybersecurity, privacy protection, and crisis management in e-government implementation. The research on e-government in China can also benefit from developing and testing indigenous theories as well as using experimental design, big data analytics, and mixed methods.

In Chapter 8, May Chu and Pak Wan Major Pau discuss the forms and components of a comprehensive regulatory system, which includes standard-setting, enforcement and self-regulation. They then introduce the concept of regulatory competition in which regional governments are competing in establishing more rigorous or loose regulations to attract foreign investments. Under such internationalized force, a nation, especially a developing one, is increasingly affected by the interests of its global stakeholders, while attempting to balance that of its citizens. Next, Chu and Pau choose China's food safety regulatory regime to illustrate how a developing nation balances between enhancing the quality of its export food products and maintaining a low operational cost for its domestic food producers. Two different systems of food safety regulatory regimes (differences in standard-setting, information gathering and behavior modification) have thus emerged in China, based on the location of the market. Chu and Pau show that if a product is exporting to a foreign country, related international safety standards are likely to be directly adopted for the industries to follow with no room for the 
latter to negotiate. These industries are frequently inspected in a rigorous manner, and their operating licenses are easily suspended or revoked if any safety hazards are detected. On the contrary, if a product is targeted at the domestic market, with a comparative purchasing power, big and small producers are allowed to participate in the standard-setting process, making the process more inclusive and transparent. These industries are less frequently inspected by authorities and are less likely to face deterrent measures when wrongdoings are detected.

In Chapter 9, Hanyu Xiao and Jingyuan Xu observe that fiscal transparency has been viewed as a proxy for good governance and a remedy for curbing corruption. Taking China's fiscal transparency development as an example, Xiao and $\mathrm{Xu}$ examine whether this view holds true in China. They first review the progress of fiscal transparency in China since the implementation of its open information policy. Next, Xiao and Xu conduct an analysis of the concentrated costs and dispersed benefits of fiscal transparency in the Chinese context. Xiao and $\mathrm{Xu}$ then evaluate the impact of fiscal transparency on corruption, fiscal accountability, and an administratively open culture. Xiao and Xu find that we should not have high expectations of fiscal transparency and conclude with comments on the potential for further development of fiscal transparency in China.

In Chapter 10, Xigen Li examines how the PRC's internet and media policies adapt to the changing media landscape in China, due to the advancement of media technology and the emerging media usage patterns. Compared to the age of the traditional media, there are visible changes to the fundamental changes with regard to media landscape. Despite of the fact that the newspapers and television continue to be controlled by the government, online and social media in various forms have emerged. It is no longer the case that official media dominate information production and delivery. Along with the growth of online and social media, people can produce and publish information and express views in information channels other than the traditional media. Thus, information production and delivery are no longer totally under the control of the government, and could sway far away from the government guidelines. Li reports that along the different stages of the online and social media development and the media landscape change, the Chinese government established a series of laws and regulations to confine and guide the information production and dissemination via online and social media. Through a documentary analysis of the laws and regulations created and enacted by the Chinese government on internet information governance since 2000, and a case study of social media vocal Big Vs who were cracked down by the Chinese government after they became the symbol of the civil voice in the virtual world, Li addresses several key questions regarding how people communicate and share information through different digital platforms and raise problems that concern the government. Li also illuminates how the Chinese government rules online and social media with its internet and media policies initiated and adapted to the changing media landscape to gain control over the information production and distribution in the digital world.

In Chapter 11, Fen Lin draws attention to the Regulation of the People's Republic of China on Open Government Information (OGI, The Regulation) issued in April 24, 2007. Lin argues that since the OGI regulation went into effect on May 1, 2008, it has become one of the most important legal documents that defines authoritarian transparency as well as one of the most popular legal citations in China's courts. Lin discusses the study of Open Government Information Regulations in three comparative aspects. First, Lin introduces the history of OGI regulations in China and locates the development of OGI legislation in the background of global diffusion of Freedom of Information laws. Second, Lin compares the existing studies 
on Freedom of Information laws across nations. Lin highlights three research domains in these studies: diffusion of legislation; implementation of laws/regulations; and impacts of laws/regulations. Finally, Lin discusses the research challenges and opportunities of studying China's OGI regulations and explores the implications on the information transparency and government accountability in an authoritarian regime.

In Chapter 12, Alfred M. Wu and Fangzhi Ye explore the nature of China's land use rights system, its evolution and impact on resource allocation and local governments' public finances. In recent decades, the public ownership of land has not hindered the development of a thriving market economy. Since the inception of the economic reform, land use rights, a new institution, have been introduced to address the rigidness and ineffectiveness of land ownership in China. The current land use rights system has provided enterprises and individuals with a largely stable land tenure system while permitting local governments to leverage land finance for infrastructure investment. Nevertheless, rampant corruption and predatory behaviors by local governments are associated with land transactions, which pose a threat to social stability at the grassroots level. The Chinese experience sheds fresh light on the development of a sound land administration system in developing countries.

In Chapter 13, Yangbin Chen critically reviews a swarm of research literature surrounding China's ethnic minority policy. Chen argues that beneath the contestation on Chinese ethnic minority policy between Chinese and the Western narratives, there emboldens a desire of forming a Chinese discourse, which is manifestation of a "Chinese model" in addressing ethnic minority issues. Chen adopts the binary political-cultural framework of the "Chinese model" to unfold the historical trajectory of Chinese ethnic minority policy since the founding of the PRC in 1949. Chen argues that the socialist political ideology and Confucian cultural tradition, explicitly and implicitly, constitute two fundamental imperatives behind China's party state's ethnic minority policy discourse, which is often conflicting with its counterpart of Western discourse: universal minority rights and politics of identities in liberalism.

In Chapter 14, Lucy Zhao, Xiaowei Zang, and Shijia Yang examine the Chinese foreign language education policies. They understand that foreign language education policies of a country are influenced by various factors, such as national ideology, politics, economy, culture and so on. In the West, scholars put forward some theories on how to study foreign language education policy scientifically, such as the economics of language, the language ecology, grassroots politics, and so on. Through a detailed analysis of Chinese foreign language education policies since 1949, they find that the development of Chinese foreign language education policies has gone through four distinguishing periods, and its choice of the first foreign language and other foreign languages has fluctuated in different historical periods. In addition, when applying existing theories such as the economics of language and the language ecology to the reality of China, they find that both theories can be applicable to Chinese foreign language education policies but with certain limitations. The reason is that the formulation of these foreign language policies made by the Chinese government are guided by the political needs of the country. They examine the elite discourse on the Chinese dream to understand the political dynamics of the changes in Chinese foreign language education policies from 1949. They conclude that the effect of the elite discourse on the Chinese dream needs to be taken into account when researching government policies on foreign language education in China. 


\section{Part IV: Public Administration and Governance in China}

The chapters in this section examine issues related to government and governance in general and policy implementation in particular in the PRC. In Chapter 15, Yu Song offers historical review of family planning policies in connection to fertility changes in the PRC. Song argues that since the founding of the socialist regime in 1949, China's family planning policies have undergone tremendous changes due to its drastic political, economic and social changes. Drawing on China's national population statistics, Song analyzes China's family planning policies and fertility changes in a dynamic, historical context. Song divides China's family planning policies into three stages and nine sub-stages in terms of its scope and rigidness: the pre-family planning stage, the family planning stage and the later-family planning stage. In line with the changing family planning policies in China, Song shows that the total fertility rate has dropped radically from over 6 in 1949 to below 2 in the early 1990s and then continued its downward trend.

In Chapter 16, Xiaoling Zhang examines how the explosive growth in China's urban population has invited inevitable conflicts in the process of human-environmental interaction, which may render a new social-economic-ecological landscape in the post-urbanization era. Zhang analyzes the unique facts, policies, and implementation activities of China's urbanization over the past two decades. First, Zhang introduces the administrative structure of the urbanization policy system in China and assesses the process of policy options under multiple objectives. Next, Zhang discusses the theoretical frameworks of urbanization and offers a critical assessment of sustainable urbanization policy in China. Zhang then studies the risks, challenges and externalities in Chinese sustainable urbanization. Zhang concludes the chapter with a discussion of various features associated with China's urbanization mode at different levels to provide implications for future research and policy design, and further suggests a broader perspective in examining sustainable urbanization policy.

In Chapter 17, Wai-Fung Lam and Wei Li examine the role of state-society interactions in governance in China by conducting a comparative analysis of the structure and processes of collaborative innovation of two government-funded community-based, elderly service networks in Shanghai. Lam and Li find that in line with the literature, a network that has an organized administrative organization structure is better able to manage the process of service innovation in a way that balances the need to achieve government policy goals on the one hand and the imperative to facilitate bottom-up citizen participation on the other. Contrary to what existing studies have suggested, Lam and Li found that a network in which a lead organization plays a dominant role, despite its more centralized process of service innovation, is often able to deliver a variety of high-quality and low-cost services addressing citizens' needs. With the leadership provided by the network lead organization and its close affiliation with the street-office government, the network has been able to solicit government support. Such a hierarchical yet responsive state-society relation has emerged as a result of the coalescence of a corporatist state legacy and an increasing pressure demanding for local governments to seek citizens' support in service delivery in China.

In Chapter 18, Hongping Lian, Hui Li, and Kilkon Ko examine China's growing transactions of urban land use rights (LURs) and the resultant rampant illegal land use since the 2000s. Their research question is whether LURs were appropriately used to advance the public interest. In response to such concerns, beginning in the $2000 \mathrm{~s}$, the Chinese central government urged local governments to adopt the market-led transaction (MLT) approach. 
Using a multi-level analysis model with a two-level structure (time and province), Lian, Li, and Ko examine whether the MLT reform has reduced illegal land use by local governments, as the central government intended. Their study shows that even after controlling for yearly and provincial variations, a 1 percentage point increase in the MLT adoption rate results in a 0.765 percent decrease in illegal land use cases and a 1.45 percent decrease in illegal land use area respectively. The adoption of market-led transactions in the 2000s seemingly intends to prevent an increase in illegal land use during a period of rapid economic and urban development. Also, the MLT adoption rate continuously increased, reaching 43.4 percent in 2008; after 2008, the trend was reversed and the MLT adoption rate dropped to 27.0 percent in 2012. Lian, Li, and Ko suggest that the Chinese government should continue to utilize market mechanisms as a policy instrument to curb illegal land use and also try to close institutional loopholes to improve implementation.

In Chapter 19, Xiaowei Zang asks whether the Chinese government has played a key role in wastewater treatment in China, and whether Chinese citizens have been a major actor in pollution control in China. Zang addresses these two questions by exploring the effects of government capacity and citizen activism on wastewater treatment in China. Zang measures government capacity in terms of regulatory enhancement (e.g., legislative motions) and resource allocation (e.g., earmarked budgets and environmental personnel recruitment) for pollution control. These measures manifest the commitment and capacity of a local government to protect the environment in its jurisdiction and are the mechanisms whereby government policies become effective tools of wastewater treatment in China. Zang measures citizen activism in environmental protection in terms of (1) personal visits to local government offices by concerned citizens to register their request to address an environmental issue and (2) complaint letters against polluters from the public to government offices. Zang discusses a provincial panel dataset on wastewater treatment for the period of 2004-2014 for empirical tests. Next, he outlines the levels of water pollution and reviews the existing literature on wastewater treatment in China. Zang then conducts empirical tests to evaluate the relationship between government capacity, citizen activism, and wastewater treatment in China. Data analyses show the important role of government capacity in wastewater treatment in China. However, there is little evidence of public environmentalism on wastewater in China.

In Chapter 20, Ruiping Fan and Chunyan Ding discuss how policy makers can learn from international experiences and adopt proper motivational measures to promote organ donation in China and Hong Kong. Fan and Ding identify three prominent international models of organ donation pertaining to motivation, which can be termed liberalism, compensationalism, and familism, respectively. Fan and Ding construct the features of these models by the following factors: the characteristic incentives adopted by the respective models to motivate individuals to donate organs, the fundamental cultural values underlying each model, and the outcomes of donation resulted from the models in the United States, Iran and mainland China. Fan and Ding find that none of these three different models should overwhelmingly be affirmed as a whole for making recommendations to every country and region to embrace. Rather, there are meriting and advantageous elements in each model that should be integrated to shape a group of incentive measures to improve donation in every society in general and mainland China and Hong Kong in particular. A suitable goal for relevant policy and administration is to confirm and promote practically effective, ethically justifiable, and politically legitimate incentive measures for organ donation in China and Hong Kong. 


\section{Part V: Street-Level Bureaucracy in China}

The four chapters in this section study street-level bureaucracy to understand how policies and regulations are implemented at the street level by frontline bureaucrats in China. In Chapter 21, Xiaowei Zang reviews research on street-level discretion and its relevancy for frontline work in China. Street-level bureaucrats includes police officers, teachers, social workers, and the like. Discretion refers to their capacity to follow or deviate from rules and procedures to address client circumstances and needs. Lipsky (1980, xii, 84) argued

that the decisions of street-level bureaucrats, the routines they establish, and the devices they invent to cope with uncertainties and work pressures, effectively become the public policies they carry out. I (Lipsky) argue that public policy is not best understood as made in legislatures or top-floor suites of high-ranking administrators, because in important ways it is actually made in the crowded offices and daily encounters of street-level workers.

Since 2000, Chinese scholars began to do research on street-level bureaucracy. Some reviews of the English literature on street-level bureaucracy have been published in China. Compared with the existing Chinese reviews, Zang provides a more substantial and updated summary and assessment of the literature on street-level discretion. Zang also raises some critical issues for future research on frontline discretion in China.

In Chapter 22, Jianhua Xu, Qipu Hu, and Anli Jiang provide a review of current research on Chinese policing. This chapter examines how recent political and economic developments in China affect empirical research in this area. The regime nature of Chinese party-state as an authoritarian capitalism has clear footprints in policing studies in China. More specifically, three group discourses surrounding authoritarian capitalism are identified in literature. First, scholars have widely explored how authoritarianism affects Chinese policing. It is found that due to its authoritarian politics, related police work has centered on increasing performance legitimacy for the party-state. The securitization of the Chinese state has impactfully affected police operation. Police violence and corruption have suffered from a lack of accountability in authoritarian politics. Low police morale is observed under the authoritarian model of policing. Second, scholars have examined how market logic under capitalism penetrates into policing. They find that policing has increasingly become a commodity tradable in the market. The principle of cost-saving and efficiency can also be seen in policing civilianization and outsourcing. Third, Chinese policing is evolving toward a soft-authoritarian policing model as many soft-line tactics are adopted along its authoritarian way of law enforcement. This chapter ends with suggestions for future studies on Chinese policing.

In Chapter 23, Xiaowei Zang and Michael Musheno examine discretion in frontline work in China. Drawing upon a survey $(\mathrm{n}=1,721)$ of Chengguan (city management) officers in urban China, Zang and Musheno explore the influence of autocratic one-party rule on the meaning of and variation in rule compliance in China. They find that the majority of Chengguan officers are rule followers, and demographic differences show little effect in deviations from this norm. However, institutional factors associated with one-party rule, particularly upward accountability, the privilege of administrative rank, and unequal access to power and resources, are significant in making differences in rule-following among Chengguan officers. Zang and Musheno conclude with a discussion of the similarities in institutional pressures on urban regulatory policing in China and the United States. In a way, this chapter breaks new ground by conducting an institutional analysis of rule compliance in the PRC. 
In Chapter 24, Lisa Zang and Xiaowei Zang examine the main causes of leniency and severity in street-level law enforcement in China. Their research questions attest to that given a civil offense in China, how many adjudications are harsh punishments and how many of them are lenient treatments? Who are likely to receive legal leniency? Zang and Zang briefly review the history of severity and leniency in China's legal system and discuss two possible institutional bedrocks of severity and leniency by Chengguan officers: political expediency and Confucian benevolence. Zang and Zang examine patterns of civil law enforcement among Chengguan officers and find that while there was severity during the course of law enforcement, there was leniency toward some groups of street venders if they were the elderly, women, disabled, and so on. Zang and Zang explain the variation in severity and leniency in terms of the government policy of balancing leniency with severity and Confucian tradition of leniency and severity.

\section{Part VI: Research and Teaching on Public Administration in Greater China}

The last section of this Handbook includes three chapters to review PA teaching and research in mainland China, Hong Kong, Macau, and Taiwan. In Chapter 25, Yijia Jing examines dissertation research in PA in China. Using the evaluation framework originally developed by McCurdy and Cleary (1984), Jing examines the quality of 132 dissertations successfully defended by public administration doctoral students in Mainland China between 2002 and 2006. Jing argues that in general, the quality of these PA dissertations was inadequate in six criteria: research question, validity, theory relevance, causality, importance, and innovativeness. Jing further reckons that major institutional problems have led to such inadequacy, including the lack of a research orientation, inflexible $\mathrm{PhD}$ advisory arrangements, and difficulty to adapt to internationalization. Real efforts and institutional reforms are urgently needed to build $\mathrm{PhD}$ education and research of PA on contemporary social science standards.

In Chapter 26, Echo Lei Wang and Jie Gao observe that the PA literature of Hong Kong and Macau has grown substantially in the past decade, yet an up-to-date literature review on the recent development of the field is still lacking. The latest review of studies was done by Gao (2014) using a sample size of 113 papers collected on Hong Kong and 223 papers on Macau published between 1999 and 2009. Wang and Gao adopt the same data sources, data collection method and analytical factors but for an updated period from 2010 to 2019 to do the study in this chapter. Wang and Gao gather a total of 782 journal articles, with 478 articles on Hong Kong and 304 articles on Macau, published from 2010 to 2019. They examine various issues including research topics, methodologies, purpose and style, and author profiles. Wang and Gao find that studies on Hong Kong are found to be more methodologically rigorous in terms of theory-building and examining, and they cover a wider scope of topics with emphases on governance, development and public management reform. The Hong Kong academic community has attracted broader international participation and resources. Studies engaging Macau, on the other hand, are significantly less quantitative and more descriptive with greater contribution from social institutions and practitioners, while they cover a narrower range of topics with shorter time spans and less international funding. Wang and Gao suggest that the discrepancies in research, while reflecting the academic capacities of Hong Kong and Macau as intellectual hubs, could be a result of diverging political and administrative challenges and concerns the two city-states individually face under the post-colonial constitutional framework. 
In Chapter 27, Milan Tung-Wen Sun, Wen-Hsueh Chen, and Windy Thi-Ngoc-Minh Phan claim that in the past 30 years, the public administration community in Taiwan has taken shape, but the community itself still faces the problem of integrating theory with practice. There is a lack of communication between the academics' and the practitioners' community, as these two communities focus on different issues and embody different governing structures (governance vs. government) for problem-solving. Not only are their related issues different, but also theories and concepts are less discussed in the practitioners' community. The two communities become less and less relevant to each other. Over time, the crisis of relevance may evolve into the "crisis of confidence," in which members of the practitioners' community do not have confidence about whether knowledge or exemplary practices produced in the academic community can be beneficial to their daily problem-solving. In the long run, the professional status of PA may be questioned, and it may lead to the "crisis of legitimacy" in which the discipline of PA is at stake.

According to Sun, Chen, and Phan, a great part of the reasons for the growing distance between the two PA communities stems from the different emphases and demands from different institutions in Taiwan: the central government stresses the importance of forward-looking policy planning research in Taiwan as a whole; local governments prefer policy evaluation research which emphasizes the conditions, demands, and satisfaction of local stakeholders about local services in different parts of Taiwan; and the topics of government-funded journals are quite diverse, as the agencies which sponsor the journals are targeting at different audiences. There is a pressing need to address the issue of relevance if PA research and practice are to advance in the future.

\section{SUMMARY AND DISCUSSION}

To sum up, there are altogether 27 chapters in this Handbook. The chapters in this Handbook advance research on PA in China significantly in two aspects. First, research publications on PA in China have mushroomed in recent years. Yet they address different PA issues in the PRC and are scattered across a large number of books and academic journals in and outside China. This Handbook identifies some important research topics and arranges them systematically to establish a broad framework for the future study of PA in China. Second, this Handbook consolidates knowledge scattered in different disciplines and provides readers with a multidisciplinary and multifaceted coverage of major issues on PA in China in one single volume. The chapters in the Handbook address some conceptual, theoretical, and methodological issues in the study of PA in China. They offer critical reflection on where the field has been and where it is going. These chapters turn this Handbook into a convenient reference, offering an overview of key issues in research on PA in China.

With regard to the future study of PA in China, we agree with Kim et al. $(2019,757,761)$ that PA scholars "could address the complexity of Chinese public administration by applying diverse methodologies," and "the following eight fields may be fruitful in generating pertinent publications: nonprofit management; emergency management; global comparative public administration (including the PRC); intergovernmental relations; public-private partnerships (PPPs); environmental protection; climate change; and performance measurements and improvements." We urge pro-active efforts by mainland Chinese PA scholars to broaden their collaborative links with their counterparts outside China, since this would be an effective and 
fast way for them to increase quality research outputs in top international journals. They shall also actively recruit Chinese students with $\mathrm{PhDs}$ from top universities in the world and create good working environments for the returned Chinese $\mathrm{PhD}$ holders to flourish in China.

Finally, while acknowledging the increasing number of mainland Chinese PA scholars who have published in top research outlets, we draw attention to the critics of research on PA in China (Chow, Xiao, and Wen 2018; Jing 2008; Lu and Chow 2008; Walker, Brewer, and Choi 2014; Wu, He, and Sun 2013) that if the mainland PA community aims to enhance its global profile and reputation in research on PA, it shall make efforts to move away from descriptive and atheoretical studies, follow the standard formats for mainstream social science research such as a reasonable amount of references for an output, promote theoretical innovation, improve the research methodology, and conduct empirical examinations rigorously so that it can produce more high-quality works by international standards for the social sciences, and its research becomes a more important part of global efforts for knowledge production in PA. We hope that the chapters in this Handbook can contribute to the efforts by the mainland PA community to internationalize the future study of PA in China.

\section{ENGLISH REFERENCES}

Behn, Robert (1995) “The Big Questions of Public Management.” Public Administration Review 55(4), 313-324.

Cartwright, Mark (2019) “The Civil Service Examinations of Imperial China.” February 8. https://www .ancient.eu/article/1335/the-civil-service-examinations-of-imperial-china/, accessed January 20, 2020.

Cheng, Joseph and Lucia Lu (2009) "Public Administration Research in China: Evidence from Content Analysis of Leading Chinese Public Administration Journals." Issues \& Studies 45(1), 203-241.

Chow, King (1991) "Public Administration as an Academic Discipline in China." In: Ali Farazmand (ed.), Handbook of Comparative and Development Administration. New York: Marcel Dekker, 409-420.

Chow, King, Haiyan Xiao, and Mingyue Wen (2018) “The Maladies of Chinese Public Administration.” Transylvanian Review of Administrative Science 18(3), 18-31.

Chow, King, Zhihang Xu, and Mingyue Wen (2019) “The Evolution of Chinese Administrative Studies." Journal of Chinese Political Science 24(1), 145-159.

Fritzen, Scott (2010) "Envisioning Public Administration as a Scholarly Field in 2020." Public Administration Review 70(S1), 300-301.

Gao, Jie (2014) "Public Administration Research in Hong Kong and Macau: A Review of Journal Articles Published from 1999 to 2009." The American Review of Public Administration 44(2), 168-186.

Harris, Peter (2002) "The Origins of Modern Citizenship in China." Asia Pacific Viewpoint 43(2), 181-203.

Holzer, Marc and Mengzhong Zhang (2002) “Chinese Public Administration Review.” Chinese Public Administration Review 1(1), 5-8.

Holzer, Marc and Mengzhong Zhang (2009) "Introduction to the Special Issue on Comparative Chinese/ American Public Administration." Public Administration Review 69(1), S5-S12.

Jing, Yijia (2008) "Dissertation Research in Public Administration in China." Chinese Public Administration Review 5(1/2), 27-38.

Jreisat, Jamil E. (2005) “Comparative Public Administration is Back in, Prudently.” Public Administration Review 65(2), 231-242.

Jreisat, Jamil E. (2011) "Commentary - Comparative Public Administration.” Public Administration Review 71(6), 834-838.

Kim, Min-Hyu, Huafang Li, Marc Holzer, and Mengzhong Zhang (2019) "Public Administration Research in Mainland China: A Systematic Review of Chinese Public Administration in English Language Journals (1996-2016)." International Journal of Public Administration 42(9), 753-764. 
Li, Xiufeng, Yadong Han, and Pan Suk Kim (2018) “The Development of China's Public Administration Education." Teaching Public Administration 36(2), 163-177.

Lipsky, Michael (1980) Street-Level Bureaucrats. New York: Russell Sage Foundation.

Liu, Wei and Wenzhao Li (2013) "Public Administration in China - Evolution and Current Challenge." Asian Journal of Political Science 21(1), 1-20.

Liu, Yichang (1993) “An Insider's Perspective: The Development of Chinese Administrative Science.” In: Miriam Mills and Stuart Nagel (eds.), Public Administration in China. Westport: Greenwood Press, 133-144.

Lo, Shiu Hing (2014) “The Study of Public Administration in Hong Kong and Macao.” Asian Journal of Political Science 22(1), 20-44.

Lu, Lucia and King W. Chow (2008) "Monitoring the Growth of Chinese Public Administration Knowledge." Chinese Public Administration Review 5(1/2), 7-25.

McCurdy, H. and R. Cleary (1984) "Why Can't We Resolve the Research Issue in Public Administration?" Public Administration Review 44(1), 49-55.

Mills, Miriam and Stuart Nagel (1993) (eds.), Public Administration in China. Westport: Greenwood Press.

Mingus, Matthew and Zhu Jing (2016) “The Big Questions of Chinese Public Administration Research.” Administration \& Society 49(6), 775-797.

Miyazaki, Ichisada (1981) China's Examination Hell: The Civil Service Examinations of Imperial China. New Haven: Yale University Press.

Tong, Caroline Haiyan and Jeffrey Straussman (2003) "A Master of Public Administration Degree with Chinese Characteristics.” Journal of Public Affairs Education 9(2), 105-115.

Walker, Richard, Gene Brewer, and Yujin Choi (2014) "Public Administration Research in East and Southeast Asia." The American Review of Public Administration 44(2), 131-150.

Wang, Lefu (2006) "A Probe into China's Public Administration Education and the Construction of the Subject of Public Administration.” Chinese Public Administration Review 1(1), 31-36.

Wu, Xun and Jingwei He (2009) "Paradigm Shift in Public Administration." Public Administration Review 69(S1), S21-S28.

Wu, Xun, Yanling He, and Milan Tung-Wen Sun (2013) "Public Administration Research in Mainland China and Taiwan." Public Administration 91(2), 261-280.

Xue, Lan (2019) "On the Future of Public Policy Schools, in Developing Countries." Global Policy $10(1), 102-103$.

Yang, Lihua (2018) "Public Administration as a Dynamic Balance and Integrative Science across Politics, Management, and Law." American Review of Public Administration 49(2), 79-97.

Yu, Wenxuan, Marilyn Rubin, and Wei Wu (2012) “An Executive MPA Program for China.” Journal of Public Affairs Education 18(3), 545-564.

Zhang, Cheng F. (1993) "Public Administration in China." In: Miriam Mills and Stuart Nagel (eds.), Public Administration in China. Westport: Greenwood Press, 3-20.

Zhang, Wei, Xiaolin Xu, Richard Evans, and Feng Yang (2018) "Towards Internationalization: A Critical Assessment of China's Public Administration Research in a Global Context 2000-2014." International Public Management Journal 21(1), 74-104.

Zhao, Yongfei (2008) "Three Waves of Public Administration Education in China." Chinese Public Administration Review 5(1/2), 49-60.

\section{CHINESE REFERENCE}

马骏/刘亚平 (2007) “中国公共行政学的“身份危机”.”《中国人民大学学报》第 21 卷第4期, 8-12. 